\title{
Investigating Technology Awareness and Usage in Mauritian SMEs in the Handicraft Sector
}

\author{
Baby Gobin- Rahimbux \\ University of Mauritius
}

\author{
Zarine Cadersaib \\ University of Mauritius
}

\author{
Nuzhah Gooda Sahib \\ University of Mauritius
}

\author{
Maleika Heenaye- \\ Mamode Khan \\ University of Mauritius
}

\begin{abstract}
Small and Medium Enterprises (SMEs) significantly contribute to economic growth of any country. In fact, in Mauritius, there are many SMEs but these SMEs face several challenges which could partially be solved through technology adoption. However, it has been observed by that there is low technology usage by these SMEs despite several initiative from the Mauritian government. Moreover, our investigation in this study revealed that there was no concrete research regarding the IT usage or the factors affecting technology adoption by SMEs in Mauritius. The motivation for this paper is therefore set towards this direction in an attempt to contribute in this area and to identify the barriers related to technology acceptance and adoption in Mauritius in the handicraft sector. A literature review has been conducted to identify various factors/components affecting technology adoption among SMEs which have been used as a driver for conducting the survey. The survey results are then discussed focusing on awareness and usage.
\end{abstract}

\section{General Terms}

Small and Medium Enterprises, Technology Acceptance

\section{Keywords}

Technology Awareness, Technology Acceptance, Technology Usage, SMEs, Handicraft Sector

\section{INTRODUCTION}

Small and Medium Enterprises (SMEs) have the ability to significantly contribute to economic growth of any country. There are at present many SMEs in Mauritius which have been created for the sustainability of many households. However, these SMEs also face challenges from other emerging markets, for example, a highly competitive environment in which to conduct their business. Therefore, in order to improve their competitiveness, quality and productivity, Mauritian SMEs have to adopt new technologies [1]. The Small and Medium Enterprises Development Authority (SMEDA) is a parastatal body in Mauritius committed to promote and empower SMEs to face challenges related to globalisation [2]. Without the adoption of technology, SMEs in Mauritius will have a low profile and capacity compared to foreign SMEs and in order to sustain their future needs, it is an undisputed fact that the SMEs in Mauritius should provide services that meet international norms.

Due to low technology usage of SMEs, basic IT training are provided by SMEDA. Despite this initiative, SMEDA has observed that a significant percentage of the concerned SMEs have not adopted these new technologies in their day-to-day activities. This implies that there are still obstacles regarding technology acceptance and usage. As at now no detailed and in-depth work and discussion regarding the IT usage and the factors affecting IT adoption by SMEs in Mauritius has been identified. This paper attempts to cater for this breach by addressing the following research questions with regards to Mauritian SMEs in the Handicraft sector.

RQ1: What is the current status of SMEs in Mauritius regarding technology awareness, acceptance and usage?

To address the above question the following set of questions were asked to Mauritian entrepreneurs belonging to one sectors of Mauritian SMEs namely the handicraft sector.

RQ1.1: Are entrepreneurs aware of the technologies that can be used to conduct their business?

Through this research question, the aim was to find out whether SMEs in the handicraft are aware of technologies that could support them in their business activities. For example, an entrepreneur may not be aware of a technology such as Microsoft Word or Excel.

RQ1.2: Do entrepreneurs accept that technology can be used to conduct their business?

This research question addressed the fact that despite being aware of the existence of technologies and using them for personal use, entrepreneurs may not accept that they can be used to conduct business. For example, someone may not think that Facebook can be used for business despite having a personal Facebook account.

RQ1.3: What kind of technology users are among SMEs and how do they use technology for the day-to-day operations of their business?

For this research question, four different components of business activities were identified, namely, Customer, Supplier, Stock and Marketing. These components are also used to classify the type of technology users among SMEs in the handicraft sector, ranging from non-users to high-users.

RQ1.4: What are the factors that impact on SMEs' acceptance and usage of technology?

Despite being aware of technologies and accepting that they may support business activities, previous work shows that SMEs sometimes do not employ technologies for various reasons. Hence, through this survey, the factors and barriers to technology acceptance among SMEs in the handicraft sector are investigated.

The paper presents the work done with respect to these research questions. The methodology used to answer these questions in presented sections 3 and 4.

\section{REVIEW OF RELATED WORK}

There are many publications discussing technology acceptance. Many focus on the technology acceptance models which include models like the Theory of Reasoned Action(TRA) [3], Theory of Planned Behaviour [4], Technology of Acceptance (TAM1 \& TAM2) [5], UTAUT 
[6], TECTAM [7], MOPTAM[8], STAM [8] and TaskTechnology Fit Model (TTF)[7]. These models present factors which impact on the acceptance of technology. Various research have been conducted worldwide to understand and analyse technology acceptance among SMEs. In this section, ten of these research are reviewed falling in the period $2001-$ 2014.

\subsection{Related works}

\section{- $\quad$ Paper 1 [9]}

The research conducted by [9] reveals that even though South Africa is developed with modernized ICT infrastructure compared to Saharan Africa societies with lack of education and unemployment, SMEs are still a source of income. The paper focuses on how far ICT can be analyzed for economic development of SMEs in developing countries. The aim to the work was to determine whether the use of ICT (as production technology, as information processing technology or as information communication technology) were able to cope with these new challenges faced by South African. It is reported that SMEs are often disadvantaged due to certain factors such as remote location, economies of scale in production and marketing, lack of access to capital and inputs etc. External transaction costs are associated with the initiation, negotiation and enforcement of contracts. From the analysis conducted, it is deduced that the Internet helps to screen the enterprises' environment for relevant information and thereby get information about sellers and customers that were previously out of reach. It is also concluded that with the use of ICT, transaction costs could be lowered and therefore the economies of scale in exporting can be reduced. This helps the SMEs to expand regionally and internationally instead of depending only on the local market. It is also concluded many SMEs that are located in rural areas, serve the local niche market and are protected against competition from bigger enterprises. This is due to the of high transport and communication costs. Thus, it was found that ICT might also increase competition for these enterprises.

\section{- $\quad$ Paper 2 [4]}

Ref [4] focus on technology acceptance at the individual level and shows that although extensive technology acceptance models exist, there is a lack of information to help understanding of technology acceptance decisions. The three models studied in this paper are TRA, TPB and TAM. Several research work were studied in five broad areas: 1) educational sector, 2) SME, 3) general public and 4) manufacturing environment to determine the usefulness of TAM in Malaysia. Their study support that the TAM model helped in "predicting and explaining use of or the intention to use a particular technology". Ref [4] proved that there is a high correlation between perceived usefulness and technology usage. However, although it was found that perceived ease of use helps in predicting perceived usefulness, it does not necessarily relate to usage or intention to use. It was also found that external factors such as prior experience and education, could impact on technology usage and adoption. For the Malaysian context, it was found that perceived usefulness led towards technology acceptance. Perceived usefulness was therefore used to improve technology usage among individuals.

\section{- $\quad$ Paper 3 [10]}

The authors in [10] investigates on the use of wireless network technologies in businesses and SMEs in the United
States. In this work, the UTAUT model was used to investigate and analyses the user acceptance of the technology. From the study, it is deduced that the UTUAT model is used for large organizations and cannot be immediately adopted in the context of WLANs since it present a unique set of circumstances. In this research work, a survey has been constructed based on the questions of UTAUT and 200 responses were received. The four direct determinants namely: influence of performance expectancy on behavioral intention, influence of effort expectancy on behavioral intention, influence of social influence on behavioral intention and Behavioral intention were analysed to determine the acceptance and usage behavior.

\section{- $\quad$ Paper 4 [11]}

Ref [11] have carried out a survey in thirteen African countries and demonstrated that there is a huge differentiation between the Informal SME sector and Formal ones. 280 SMEs were surveyed. In this work, the authors aims at understanding the effect of ICTs on private sector development, and also to show how ICTs can contribute to a vibrant SME sector and economic growth in the context of developing economies. It is reported that ICT play an important role in reducing transaction costs and thus increases efficiency. ICT can be used to find new products and to increase customer awareness of the products available. From the survey conducted, it was deduced that ICTs are important input factors for both formal and informal SMEs and contribute positively to revenue generation. The study demonstrated that there is a huge differentiation between the Informal SME sector and Formal ones. The profitability is higher for the informal SME sector. It can also be seen that the use of ICT use increases labor productivity. It was also reported that mobile phones are important tool that have overtaken computers as tools in supporting the running of SMEs and had become the default communication means. Apart from Ethiopia, there was no centralized database on SMEs thus making it more difficult to have a representative survey. The most critical barriers regarding ICT adoption were related to high cost, followed by network problems and unreliable infrastructure problems and finally followed by lack of awareness and knowledge of ICT.

\section{- $\quad$ Paper 5 [7]}

A modified version of TAM, TECTAM (Thai E-commerce Technology Acceptance Model) [7], is an expected comprehensive model to study e-commerce acceptance among SMEs in Thailand. Moreover, TECTAM is also inspired from other models such as TRA, TBP, UTAUT and TTF. The main components of TECTAM are based on perceived usefulness (PU) and perceived ease of use (PEOU) being TAM components. The short-term and long term usefulness are considered for PU. For PEOU, the social influence processes and the cognitive instrumental processes are considered. Other components include Attitude towards ECT, Intention to Use ECT, Actual ECT Use. External variable include personal factors as well as social factors. However, as per this study, TECTAM has not been validated. Moreover, the study shows that even though Thailand is advanced in technology, Thai SMEs sector are still in early stage of adopting the ECommerce.

\section{- $\quad$ Paper 6 [12]}

Ref [12] has explored the extent to which owners of small and medium enterprises (SMEs) in Malaysia are adopting communication technology (ICT) skills for running their 
business. A survey was conducted with 383 SMEs. This work differs with other previous work conducted in literature since it analyses the SME owner rather than the firm itself. The author perceived that studying the owners themselves is important because they are decision-makers who are responsible for the survival and expansion of their firms. However, it was noticed that they are often too busy and reluctant to learn ICT and eventually fail to appreciate its potential benefits to their business. The literature also reveals that the Malaysian government has initiated various incentives to persuade SMEs to adopt the Internet as a new and more efficient way of doing business. Funding was made available to SMEs to upgrade computer system upgrades, for training, technology acquisition, consultancy fees, and electronic commerce activities. Though, the analysis of the study reveals that the level of ICT skills and adoption possessed by SME are poor in Malaysia. Through the study, the authors in [12] has established the relationship various factors such as ICT skills, use, adoption patterns, and adoption categories. This study focuses on the individual innovativeness theory and the theory of perceived attributes. This has helped the author in understanding the relationship between the innovator characteristics and the adopters categories. The individual innovativeness theory is based on who adopts the innovation and when. There are five categories of adopters namely: innovators, early adopters, early majority, late majority and laggards. As for the theory of perceived attributes, the concerned individuals will adopt an innovation if they perceive that it has the certain attributes. The first attribute is that the innovation must have some relative advantage over an existing innovation or the status quo. Another attribute is that the innovation must be compatible with the existing values, past experience, and practices of the potential adopter. Thirdly, the innovation cannot be too complex nor perceived as difficult to understand. Another point is that the innovation must have trialability which means that it can be tested for a limited time without adoption. Finally, the innovation must offer observable results. The questionnaire was administered and analysed. It was concluded that there is a knowledge gap in understanding ICT adoption among the SMEs. It was seen that in previous studies that the owners of small- and mediumsized enterprises, which are an important factor, have not been considered. It was also noticed that training agencies responsible for providing ICT training to SME owners must understand how this group of adults learn and the obstacles are that they usually face. In addition, it was re-iterated that the Malaysian government has to increase its effort to create awareness among SMEs regarding the potential benefits of ICT to small- and medium-sized businesses.

\section{- $\quad$ Paper 7 [13]}

Ref [13] conducted a survey in the southeast of England with 378 small and medium sized enterprises (SMEs). The main objective of the research work was to explore the use of information and communications technology (ICT) by SMEs in this region. The sectors that were considered were food processing, transport and logistics, media and internet services. The survey was administered to obtain the following details: what types of ICT are in use by SMEs in this region, what prevents and facilitates the adoption and use of ICT amongst these firms, and where do SMEs acquire information on ICT related issues. The results of the survey reveals that sectors could be termed as traditional (for food, transport and logistics) and new (for media, and Internet). An interesting finding out of the work is that there is a difference between the traditional sector and new sector. The authors in [13] also studied the barriers related to the adoption of technology in
SMEs. It was found that costs is a major factor threatening future investment in ICT. In this work it was found that most SMEs sourced their ICT capital expenditure through retained profits. It was also noticed that large were not ICT trained or skilled and were often reliant on the advice of external consultants or vendor organisations. This affects the confidence with which they approach investment decisions concerning ICT. From the study, it was also noticed that there is a lack of resources and uncertainty on the perceived benefits, which eventually hamper the keen for training. SMEs also had a fear of technology in terms of obsolescence requiring frequent updates. The main concern for this issue is the need to find funding for updates. In this work, it was revealed that SME owner/managers perceive ICT to be often costly and complex. In addition the survey concludes that SMEs are largely unaware of existing policy instruments at the regional, national and European levels which have been administered to help them in their adoption and use of ICT.

- $\quad$ Paper 8 [14]

Ref [14] investigates SaaS readiness and adoption in South Africa which is focused on SMEs and non-profit organisations (NPOs). An adapted Perceived E-Readiness Model (PERM) (Molla and Licker's, 2005) is used to study SaaS readiness as well as SaaS adoption. This study shows that there was a significant correlation between awareness, resources and market forces (MF) for both SMEs and NPOs. Awareness contributed positively to SaaS adoption. The main factors influencing SaaS adoption as identified by this study were: awareness, security and privacy concerns, internet costs, internet reliability and access to internet and organisational resources. This study recommended that vendors provide promotions to these two targeted segments to improve SaaS adoption. It was also mentioned that the reinforcement of legal frameworks would lead towards the same direction by encouraging competition and allowing telecommunications companies to provide better rates. The limitations of this work include the small sample used for the analysis which might not be representative of all the SMEs or NGOs in South Africa. This study does not visit existing models and the deductions are made via survey result analysis.

\section{- $\quad$ Paper 9 [15]}

Ref [15] identify the factors affecting technology acceptance in Tanzania through survey results analysis. Their study does not analyse any existing technology acceptance models. The main objectives of this study were to determine the ICT adoption rate for SMEs, to assess the challenges of ICT adoption in SMEs, to assess the awareness of SMEs regarding the benefits related to ICT adoption and to assess the accessibility of ICT among various SMEs. Low ICT adoption rate in SMEs was associated to poor knowledge of ICT tools, low level of ICT tools in the SMEs sector, technical problems, high adoption costs and low emphasis on ICT usage (adoption). Possible measures to counteract these challenges were listed as follows:

- $\quad$ expansion of ICT infrastructures,

- $\quad$ provision of core ICT knowledge

- tariff reduction for imported ICT products and

- promotion of locally based ICT innovators and clients of SMEs.

\section{- $\quad$ Paper 10 [16]}

Ref [16] have investigated on the factors influencing adoption of ICT among SMEs in Tanzania. In the research work, it was 
concluded that the TAM model is suitable for investigating acceptance and use of technology and it explains much of the variance in users' behavioral intention. Perceived Usefulness (PU) and Perceived ease of use (PEOU) were two components that were used in the test hypothesis. A questionnaire was devised to capture data and 208 responses were received. In this work, it was concluded that PU of ICT technology strongly influence SMEs to adopt ICT in Tanzania.

\subsection{Findings and Discussion}

From the articles reviewed, usage and adoption were found to have the same meaning. Similar terms have been grouped based on the work reviewed. Table 1 shows a factor/component analysis based on the papers reviewed in this section. It can be seen that apart from Social Influence/factors, ICT base for SME, Security and Privacy and Market forces, all the other components are highly present in the studies reviewed. Table 2 shows a summary of the correlations found. From the above correlation it is clear that Perceived usefulness, Cost, Network/ infrastructure and Awareness/knowledge of ICT have an impact on Usage/Adoption.

Therefore in the next section, the survey has been geared towards the following factors/components: 1) Perceived Usefulness, 2) Perceived Ease of Use, 3) Usage/Adoption, 4) Awareness, 5) Attitude/ Intention to use/ Behavioural Intention, 6) Demographics (Education, Skills), 7) Cost, and 8) Training. Moreover, based on the classification of SMEs in Mauritius it was found that there is a huge diversity of SMEs in Mauritius. A tenth component, nature of business was also deemed as an important factor worth analyzing in the survey.

\section{DEVISING QUESTIONNAIRE \& CONDUCTING SURVEY}

In order to answer the set of research questions set, a survey was conducted among SMEs from the Handicraft Sector. The aim of the survey was to investigate whether SMEs in the Handicraft sector are aware of, accept and use technologies to conduct their business activities on a day-to-day basis. The section gives and overview of the instrument and the participants.

\subsection{Instrument}

A questionnaire was designed according to the objectives of the project. The questionnaire included different types of questions to investigate how SMEs in the chosen sectors use technologies. The questionnaire was also designed taking into consideration the literature review. The different technology acceptance models and their components were considered throughout the questionnaire to ensure different perspectives of technology acceptance were being investigated. The questionnaire contained sets of questions pertaining to the 4 research questions set.

\subsection{Participants}

42 entrepreneurs were surveyed. The demographics of the SMEs surveyed in the Handicraft sector are given in Table 3. 32 entrepreneurs specified their exact age, 32 specified their education level and all SMEs specified the number of years their business have been operating.
Table 1. Factor/Component Analysis based on Existing work on SMEs.

Factor/ Component

Paper ID

$\begin{array}{llllllllll}1 & 2 & 3 & 4 & 5 & 6 & 7 & 8 & 9 & 10\end{array}$

Perceived

Usefulness

Perceived

Ease of Use

Usage/Use

Behaviour/Ad

option

Awareness/

Knowlegde of

ICT tools

Attitude/

Intention to use/

Behavioural

Intention

Personal

factors/

Demographics

(Education,

Skills)

Social

Influence/

factors

Facilitating

conditions

ICT base for

SME

Security and

Privacy

Market forces

Cost
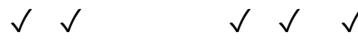
Table 2. Correlation found from Existing work on SMEs

$\begin{array}{ccc}\text { Ref [4] } & \text { Perceived usefulness } & \text { Usage } \\ \text { Ref [4] } & \text { Perceived ease of use } & \begin{array}{c}\text { Perceived } \\ \text { usefulness }\end{array} \\ \text { Ref [4] } & \begin{array}{c}\text { External factors (prior } \\ \text { experience and } \\ \text { education) }\end{array} & \text { Usage } \\ \text { Ref [11] } & \text { Cost } & \text { Adoption } \\ \text { Ref [11] } & \begin{array}{c}\text { Network/ } \\ \text { infrastructure }\end{array} & \text { Adoption } \\ \text { Ref [11] } & \text { Awareness/knowledge } & \text { Adoption } \\ \text { Ref [14] } & \text { Awareness } & \text { SaaS adoption } \\ \text { Ref [16] } & \text { Perceived usefulness } & \text { Adoption }\end{array}$

Table3: Demographics of Participants in the Handicraft Sector

$\begin{array}{lcc}\text { Sector } & & \text { Handicraft } \\ \text { Age } & \text { Primary } & 47.75 \text { years } \\ \begin{array}{l}\text { Highest } \\ \begin{array}{l}\text { Education } \\ \text { Level }\end{array}\end{array} & \text { Secondary } & 23 \\ & \text { Tertiary } & 3 \\ & \mathbf{0} \text { to 5 } & 25 \\ & \mathbf{6} \text { to } \mathbf{1 0} & 4 \\ \begin{array}{l}\text { Years in } \\ \text { Business }\end{array} & \mathbf{1 1} \text { to 20} & 6 \\ & >\mathbf{2 0} & 7\end{array}$

\section{ANALYSIS OF FINDINGS AND RESULTS}

Based on the results, obtained for the set of research questions addressed. At a confidence level of $80 \%$ the margin of error for the Handicraft sector is \pm 8 . This section gives an overview of the findings with respect to each research questions.

\subsection{Are entrepreneurs aware of the technologies that can be used to conduct their business?}

In this context, SMEs can be aware of these technologies, for example, an entrepreneur may know about MS Word even if he or she does not use it for their business. In the questionnaire, it was investigated whether entrepreneurs are aware of the following technologies, software and tools: MS Word, MS Excel, Email, Internet, Facebook, Skype, Whatsapp and Website. Figure 1 presents the data obtained for technology acceptance. Facebook is the most popular technology followed by email, Word, Internet, Skype, Excel, Whatsapp and Websites. Facebook is the leading technology in terms of awareness. It is the only technology that has an awareness rate of more than $50 \%$ in the Handicraft sector. Internet is the second most popular technology. The third most popular technology is Email followed closely by Skype.



Fig 1: Technology Awareness among SMEs surveyed

\subsection{Do entrepreneurs accept that technology can be used to conduct their business?}

Awareness of technology may lead to acceptance, that is, the recognition that technology can be useful to support business operations. Respondents were asked whether they consider specific technologies important for their businesses. Additional for those SMEs who are not currently using technology for keeping track of customers, suppliers and stock and also for marketing purposes, they were asked whether they would like to use technology for these purposes. These responses were considered as evidence of acceptance of technology, which may or may not lead to usage. The results are presented in Fig 2 and Fig 3. Fig 2 shows that although SMEs were aware about technology, this not had the same impact on accepting technology.

\section{Technology Awareness vs Technology Acceptance in Handicraft Sector}

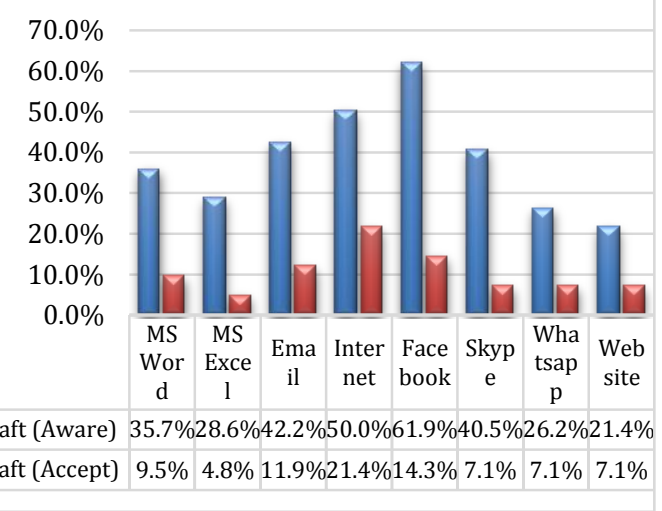

Fig 2: Technology Awareness among SMEs surveyed 




Fig 3: Intention to use technology for business operations

\subsection{How do SMEs use technology in their daily operations?}

Through the questionnaire, four main components of business were investigated, namely, Customer, Supplier, Stock and Marketing. For the Customer and Supplier components, the focus was on how SMEs interact with and keep track of their customers and suppliers. The use of technology for interacting with customers or suppliers and the use of technology to keep track of customers and suppliers contribute to the SMEs' general use of technology in their businesses. Additionally, the way SMEs keep track of their stock and the tools they employ for marketing were considered and these as well contributed to the general use of technology.

\section{- Customer}

For the respondents who currently do not use technology to keep track of their customers, they were asked whether they would like to use technology for this purpose. For the Handicraft sector, thirty-four SME do not use technology to keep track of their customers and only $55.9 \%$ of them said they would like to use technology to keep track of their customers.

\section{- Supplier}

The percentage of SMEs in the handicraft sector which use technology to interact with their supplier is $9.5 \%$. Only $4.8 \%$ use technology to keep track of their suppliers. The reason being that SMEs in Handicraft are less reliant on suppliers as they source their raw materials differently. No SME surveyed buy their raw materials on a daily basis and only $15 \%$ of SMEs buy their raw materials on a weekly basis.

\section{- $\quad$ Stock}

In the Handicraft sector, only $9.52 \%$ use technology to manage their stock. A high percentage of SMEs in Handicraft $(63.16 \%)$ who are currently not using technology want to use it to track their stock. The SMEs buy on a long term basis implying that they have to manage their stock for a longer time. This could account for the difference in attitudes towards technology for stock management.

\section{- Marketing}

Nowadays, with the advent of social media and platforms such as Facebook, digital marketing is within the reach of many small businesses. Someone who is conversant with technology and already has personal social media account(s) can easily create a social media account for their businesses. Therefore, the aim of the questionnaire was to investigate whether SMEs in the Handicraft sector. $35.71 \%$ of SMEs use technology for marketing purposes and the most common marketing approach among them is Facebook. However, among comments received through the questionnaire, some SMEs in Handicraft are also wary of social media marketing as they operate in a creative market. Among these SMEs, the feeling of insecurity was observed with respect with other SMEs copying their designs or selling at a more competitive price.

Following the analysis respective to the identified components (Customer, Supplier, Stock and Marketing), it was observed that twenty-one SME (50\%) in the Handicraft sector do not use technology in any of the components. The number of components for which each SME uses technology was also considered. This allowed the categorisation the different types of technology users, that is, those who do not use technology at all are Non Users and those who use technology in five or six components are High Users. The different categories are further explained in the Table 4. As shown in the Table 4 the majority of SMEs are non-users of IT. High users of IT are significantly low.

Table 4: Types of IT Users among SMEs

\begin{tabular}{|c|c|c|c|c|c|c|c|}
\hline $\begin{array}{c}\text { No. of } \\
\text { Components }\end{array}$ & 0 & 1 & 2 & 3 & 4 & 5 & 6 \\
\hline User Type & $\begin{array}{c}\text { Non } \\
\text { Users }\end{array}$ & $\begin{array}{c}\text { Low } \\
\text { Users }\end{array}$ & $\begin{array}{c}\text { Moderate } \\
\text { Users }\end{array}$ & $\begin{array}{c}\text { High } \\
\text { Users }\end{array}$ \\
\hline No of SMEs & 21 & 14 & 6 & \multicolumn{2}{|c|}{1} \\
\hline
\end{tabular}

\subsection{What are the factors that impact on SMEs' acceptance and usage of technology?}

There are several factors that impact the technology acceptance and usage of SMEs. In the survey, questions were included in order to confirm whether these previously identified factors are applicable to Handicraft sectors in Mauritius. The factors under study and their respective questions are given in the following table.

- Cost

Investigation was conducted to determine whether cost is a factor that influence technology usage and acceptance by SMEs. The questionnaire consisted of three questions related to cost. For the purpose of analysis, cost was considered as a significant factor for respondents who answered "Yes" to each of the three questions. For those who answered "Yes" to two questions, cost is a moderate factor and for one "Yes", cost is a low factor and for no "Yes", cost is not a factor.

For this factor, respondents were asked about the importance of subsidies, whether they would use appropriate technology if it were subsidised. The results show that $76.19 \%$ of SMEs in Handicraft would use technology if subsidies were provided for laptops and other resources. It is important to note that in Mauritius, while SMEs are given financial incentives in terms of reduced interest rates on loans, tax exemptions etc., the Government does not have a subsidy programme with regards to technology.

\section{- Training}

A high percentage of SMEs agree that training has a significant impact on the use of $\mathrm{T}$ for their business activities. Training includes seminars, workshops and demonstrations 
that teach SME owners and workers how to properly use technology in their business activities. There can be various types of training, for example, workshops on the use of general office software such as MS Excel, MS Access, MS Word etc. so that entrepreneurs can use these technologies in managing their business on a day to day basis. Training can also be in the form of specialised and targeted programmes, which demonstrate the use of specific, high tech solutions to a type of SMEs. For example, in the textile sector, operations can become more efficient through the use of Computer Assisted Drawing (CAD) software and technology-operated machines. As such, training programmes can be organised for entrepreneurs in the textile sector to show them how to incorporate these technologies in their business.

Entrepreneurs believe training will help to "learn how to use IT", "learn about new products" and "learn about new software and technologies". However, some SMEs also highlighted that to be able to benefit from free training, they will need the time to attend these training programmes. Many SMEs are reluctant to do this, as they have to take time out from the business activities to attend training. Since most of the handicraft SMEs surveyed consists of only one employee $(69.05 \%)$, attending training implies having to interrupt business activities. Therefore, unless it is clear to the SMEs the benefits that will result from these training programmes, the problems associated with reluctance will persist.

\section{- $\quad$ Perceived Usefulness}

Perceived Usefulness can be described as the perceptions of SMEs on the extent to which technology will support them in the day-to-day operations of the business. Perceived usefulness is not necessarily quantifiable in terms of revenue by the SME but it is related to the efficiency with which the business can be operated. SMEs are not convinced about the usefulness of using technology in their business. As such, $81.00 \%$ of SMEs in the sector think that technology is not required in their business and only $17.00 \%$ believes that technology can help the business day-to-day activities. Furthermore, $28.60 \%$ of SMEs in Handicraft said they would use technology if it helps to deal with suppliers and $35.7 \%$ would use technology if it helps them to manage their stock.

\section{- $\quad$ Time}

Time is a factor that has been considered in many models of technology acceptance. Many of the SMEs surveyed, especially in the Handicraft sector, are micro enterprises, that is, the owner is the sole employer. Therefore, if the sole employer takes time to learn about technologies and how to operate them, then there is the opportunity cost of being able to make more products in that time. However, the data from the survey is surprising in that SMEs $(68 \%)$ believe that time has a low impact on whether they use technologies.

\section{- Perceived Benefits}

For the purpose of this survey, Perceived Benefits (PB) was defined as benefits that can be quantified for the business. For example, increase in sales and increase in the number of customers. This is so because, small businesses measure performance mostly in terms of monetary value. Efficiency of the business processes is not of primary importance. As expected, a majority of SMEs responded that they would use technology if it helps them increase their sales and get more customers. Therefore, PB can be considered as a significant impacting factor on technology acceptance.

\section{- $\quad$ Perceived Ease of Use}

Age was considered as a potential factor affecting technology awareness, acceptance and usage. However, during the survey, the majority of participants concluded that the age of the business owner and the age of the employee does not affect their use of technology. However, among non-users of IT, the average age of the non-IT users in the Handicraft sector was 54.06 years. When compared to Moderate and High Users of IT, the average age for Handicraft was 33.8 years. Therefore, it appears that age does impact the usage of IT. It may not be conscious, but for example, the age of a person could determine whether he or she is familiar with certain technologies and know whether such technologies exist at all.

\section{- Nature of Business}

The nature of business is deemed to have a significant impact on the use of technology by SMEs. This is in line with comments gathered from entrepreneurs during the survey. For example, in the Handicraft sector, entrepreneurs face a very limited local market and given the remote location of Mauritius, very few can consider export as an option for expansion. Therefore, handicraft SMEs feel that before they can contemplate using technologies, they should be able to address the challenges related to the limited market first. On the other hand, for another sector e.g. Food SMEs, this may not the case as their products cater mainly for the local market and the sale of food items is typically more consistent.

\section{- Perceived Ease of Use}

Perceived Ease of Use can be related to how easy the entrepreneurs think it is to use technology. According to the survey, perceived ease of use has a significant impact on the use of technology in business. This can be related to the Training factor, which has also been found to have a significant impact. In fact, if SMEs are trained to use specific technologies, they will find it easier to use. For example, it may not be clear to an entrepreneur how Microsoft Excel can be used in his business, but through training, the benefits of using spreadsheets for managing stocks, accounts and expenses can be communicated. Thus, the entrepreneur will find technology easier to use.

\section{CONCLUSION}

The survey showed that Facebook was the leading technology in terms of awareness. Although SMES were aware about technology, this did not necessarily have impact on technology acceptance. Moreover, it was observed that 50\% in the Handicraft sector did not use technology in any of the components: Customer, Supplier, Stock and Marketing. Moreover, the following factors were identified to assess the impact on technology acceptance and usage that Cost, Training, Time, Perceived Benefits, Perceived Ease of Use and Nature of Business had an impact on Technology Adoption. However, the survey results showed that not all of them were relevant within the population surveyed.

\subsection{Limitations of the research}

Similar to the study carried out by the authors in [11], our study showed that although there is an authority for monitoring SMEs in Mauritius, there is not centralized SME database. In fact many contacts, as provided by SMEDA, were no more operating at this time the interview was conducted making it more difficult for a representative survey. 


\subsection{Further Research}

This research could be further extended to other SMEs sectors. From literature analysis, TECTAM [7] being an ecommerce adoption model for SMEs, could be of interest in our context, where a technology acceptance model in the Mauritian context is expected to be derived. Moreover, since the predominant components TECTAM is based on TAM [5], the latter can also be considered important in further stages of this study. The authors of TECTAM proposed to validate their model through surveys and interviews. The same direction could be followed by deriving a technology acceptance model specific for Mauritian SMEs and validation through survey and analysis. Ref [14] recommended vendors to provide promotions to SMEs and NPOs and the reinforcement of legal frameworks to improve SaaS adoption. Future research could therefore be led toward this direction.

\section{REFERENCES}

[1] SMEDA, 2014, SME Resource and Technology Centre. [Online] Available at http://www.smeda.mu/English/ Servicessmeda/SME\%20Resource\%20and\%20Technolo gy\%20Centre/Pages/Introduction.aspx. Accessed on 30 April 2014.

[2] SMEDA, 2017 SME Resource and Technology Centre. [Online] Available at_https://www.smeda.mu. Accessed on 7 March 2017.

[3] Fishbein, M., and Ajzen, I., 1975. Belief, attitude, intention and behavior: An introduction to theory and research.

[4] Ramayah, T., and Jantan, M., 2004, Technology acceptance: An individual perspective, current, and future research in Malaysia. Review of Business Research, 2(1), 103-111.

[5] Venkatesh, V., and Davis, F. D., 2000, A theoretical extension of the technology acceptance model: four longitudinal field studies. Management science, 46(2), 186-204

[6] Venkatesh, V., Morris, M. G., Davis, G. B., and Davis, F. D., 2003, User acceptance of information technology: Toward a unified view. MIS quarterly, 27(3).

[7] Chooprayoon, V., Fung, C.C. \& Depickere, A.A., 2007, TECTAM, A modified technology acceptance model to assess E-commerce technologies adoption by Thai SME. In TENCON 2007-2007 IEEE Region 10 Conference (pp. 1-4). IEEE.
[8] Renaud, K. and Van Biljon, J., 2008. Predicting technology acceptance and adoption by the elderly: a qualitative study, In Proceedings of the 2008 annual research conference of the South African Institute of Computer Scientists and Information Technologists on IT research in developing countries: riding the wave of technology (pp. 210-219).

[9] Wolf, S., 2001, Determinants and impact of ICT use for African SMEs: Implications for rural South Africa. In Center for Development Research (ZEF Bonn). Trade and Industrial Policy Strategies (TIPS), Annual Forum at Misty Hills, Mulderdrift (10th to 12th September).

[10] Anderson, J.E. and Schwager, P.H., 2004,. SME adoption of wireless LAN technology: applying the UTAUT model. In Proceedings of the 7 th annual conference of the southern association for information systems (Vol. 7, pp. 39-43).

[11] Esselaar, S., Stork, C., Ndiwalana, A., \& Deen-Swarray, M. , 2007,. ICT Usage and Its Impact on Profitability of SMEs in 13 African Countries. Information Technologies \& International Development, 4(1), 87100.

[12] Hashim, J., 2007, Information communication technology (ICT) adoption among SME owners in Malaysia. International Journal of Business and Information, 2(2), 221-240.

[13] Harindranath, G., Dyerson, R., and Barnes, D., 2008, ICT adoption and use in UK SMEs: a failure of initiatives? Electronic Journal of Information Systems Evaluation, 11(2, 91-96.

[14] Madisha, M. and Van Belle, J.P., 2011, Factors influencing SaaS adoption by small South African organizations. In 11th Annual Conference on World Wide Web Applications. Durban, South Africa.

[15] Sanga, C. and Buzingo, J., 2013, Factors influencing the adoption and use of ICT by small and medium sized enterprises in Tanzania: a case study of Kilosa district. ICT for Development Working Paper Series, p.77.

[16] Ndekwa,A.G, 2014, Factors Influencing Adoption of Internet Services among Small and Medium Enterprises (SMEs) in Tanzania. The International Journal Of Science \& Technoledge.2(12).pp261-268. 